\title{
Environmental enrichment enhances the stimulant effect of intravenous amphetamine: Search for a cellular mechanism in the nucleus accumbens
}

\author{
M. T. BARDO, J. M. VALONE, P. M. ROBINET, W. B. SHAW, and L. P. DWOSKIN \\ University of Kentucky, Lexington, Kentucky
}

\begin{abstract}
The nucleus accumbens and its related neural circuitry are known to be involved in mediating drug reward. The present brief review provides evidence that manipulation of the stimulus environment may alter the behavioral effects of drugs of abuse by altering accumbal circuitry. In experiments conducted in our laboratory, rats were raised in either an enriched condition (EC) or an impoverished condition (IC) and then were challenged with acute intravenous amphetamine. EC rats were more sensitive than IC rats to the locomotor stimulant effect of amphetamine, as well as to the accumbal dopamine release measured by in vivo microdialysis. No environment-induced difference in [ $\left.{ }^{3} \mathrm{H}\right]-$ amphetamine pharmacokinetics was observed. In vitro neurochemical experiments also indicated that accumbal tissue slices isolated from EC and IC rats did not differ in dopamine levels, electrically evoked dopamine release, or dopamine autoreceptor sensitivity. Although the kinetic parameters for $\left[{ }^{3} \mathrm{H}\right]$ - dopamine uptake into striatal synaptosomes were not different between EC and IC rats, the transport inhibitor GBR 12935 was more potent in inhibiting uptake in EC rats than in IC rats. The latter results suggest that dopamine transporter proteins in the nucleus accumbens may be an important target for future studies aimed at identifying the cellular mechanism responsible for the environmentinduced difference in the behavioral response to amphetamine.
\end{abstract}

The nucleus accumbens and its associated limbic structures have been the subject of intense investigation among researchers examining the neuropharmacological bases of the incentive and motivational aspects of various positive rewarding stimuli, including food, water, sex, and drugs of abuse. Regulation of accumbens-mediated drug effects is known to be, at least to some extent, under genetic control (Crabbe, Belknap, \& Buck, 1994). However, recent evidence indicates that this regulation is also under environmental control. In the present paper, we briefly review evidence of the ways in which environmental factors modulate the regulatory processes of the mesoaccumbal dopamine reward circuitry that is involved in mediating the behavioral effects of drugs of abuse. We will emphasize results from our laboratory showing that rats raised in either an enriched or an impoverished stimulus environment show a differential re-

We gratefully acknowledge the expert technical assistance of Susan T. Buxton, Susan Moore, Amy Williamson, and Melinda Marion in conducting the experiments. Helpful discussion with Peter Crooks on the pharmacokinetic experiment is acknowledged. The research was supported by USPHS Grants DA05312 and DA06924. W.B.S. and L.P.D. are in the Division of Pharmaceutical Sciences in the College of Pharmacy. Correspondence should be addressed to M. T. Bardo, Department of Psychology, University of Kentucky, Lexington, KY 40506 (e-mail: mbardo@pop.uky.edu). sponse to amphetamine. Some direction for future research will be offered.

\section{Neurobehavioral Effects of Environmental Enrichment}

One useful method of studying the influence of environmental factors on brain and behavior is to raise laboratory animals in different stimulus environments: an "enriched" condition (EC) and an "impoverished" condition (IC; Renner \& Rosenzweig, 1987). Research over the last 40 years has shown that environmental enrichment produces profound neuroanatomical and neurochemical changes in the neocortex, particularly in the visual cortex (Renner \& Rosenzweig, 1987; Wallace, Kilman, Withers, \& Greenough, 1992). Environmental enrichment increases neocortical weight and thickness, primarily because of an increased density of glial and capillary endothelial cells (Diamond et al., 1966; Sirevaag \& Greenough, 1988). Environmental enrichment also increases various neurochemical markers in the neocortex, including acetylcholinesterase activity (Rosenzweig, Krech, Bennett, \& Diamond, 1962), levels of norepinephrine and dopamine (Reige \& Morimoto, 1970), and densities of dopaminergic terminals in the prefrontal cortex (Winterfeld, Teuchert-Noodt, \& Dawirs, 1998). These neocortical changes may be enhanced when animals are stimulated to interact with the enriched stimulus environment 
with a low dose of methamphetamine (Rosenzweig \& Bennett, 1972).

In correlation with these neocortical changes, $\mathrm{EC}$ rats are superior to IC rats in various learning tasks using either appetitive or aversive stimuli. Although some inconsistencies in the literature exist, it has been concluded that the most reliable differences between $\mathrm{EC}$ and IC rats have been observed in studies done with complex spatial tasks (Renner \& Rosenzweig, 1987). In particular, successful navigation of a complex maze is reliably enhanced by environmental enrichment (Bennett, Rosenzweig, \& Diamond, 1970; Freeman \& Ray, 1972; Greenough, Madden, \& Fleischman, 1972).

In addition to enhancing complex learning abilities, environmental enrichment also enhances the approach response directed toward novel environmental stimuli. For example, EC rats display a shorter latency to enter a novel compartment from a protected compartment than do IC rats (Lore \& Levowitz, 1966). In addition, when tested in an arena containing novel objects, EC rats display more object contacts than do IC rats (Widman \& Rosellini, 1990). Not only is the number of contacts increased in EC rats, the behavioral diversity that they display while interacting with the novel object is also increased (Renner \& Rosenzweig, 1986; Widman \& Rosellini, 1990). Since approach to novelty is known to increase the dopaminergic activity in the nucleus accumbens (Rebec, Christensen, Guerra, \& Bardo, 1997), one explanation for these behavioral findings is that environmental enrichment may potentiate accumbal sensitivity to the effects of novelty.

Environmental enrichment may also potentiate accumbal sensitivity to the effects of amphetamine and related psychostimulant drugs. When administered acutely, amphetamine increases locomotor activity more in $\mathrm{EC}$ rats than in IC rats (Bowling \& Bardo, 1994; Bowling, Rowlett, \& Bardo, 1993). EC rats also show greater amphetamine conditioned place preference than do IC rats (Bowling \& Bardo, 1994). With oral self-administration, EC rats also show greater initial consumption of cocaine (Hill \& Powell, 1976; see, however, Zimmerberg \& Brett, 1992). These acute behavioral changes may be related to alterations in accumbal dopamine utilization, because environmental enrichment potentiates the amphetamineinduced decrease in dihydroxyphenylacetic acid (DOPAC) levels in the nucleus accumbens (Bowling et al., 1993). It is also important that, in contrast to the acute effects of amphetamine, the behavioral effects following chronic exposure to amphetamine are diminished by environmental enrichment (Bardo et al., 1995; Fowler et al., 1993; Smith, Neill, \& Costall, 1997). This suggests that different mechanisms, either within the nucleus accumbens or its related structures, are involved in the acute and chronic psychostimulant effects of amphetamine.

\section{Controlling for Potential Environment-Induced Pharmacokinetic Differences}

An important issue to be resolved regarding environment-induced differences in drug effect is the potential role of alterations in pharmacokinetic parameters. A consistent finding in the literature is that $\mathrm{EC}$ rats weigh significantly less than IC rats (Bardo \& Hammer, 1991; Fiala, Snow, \& Greenough, 1977), in part because EC rats have less adipose tissue. Since amphetamine is lipophilic, less amphetamine may be distributed to adipose stores in $\mathrm{EC}$ rats than in IC rats, thus leading to a greater distribution to the brain. In addition, relative to IC rats, EC rats may have a greater distribution of amphetamine to the brain as a result of a larger brain capillary blood supply (Sirevaag \& Greenough, 1988) and morphologically smaller livers (Black, Sirevaag, Wallace, Savin, \& Greenough, 1989). These pharmacokinetic factors may explain, at least in part, the enhanced locomotor and neurochemical effects of amphetamine in EC rats following acute systemic injection.

To assess amphetamine distribution in the brain, male Sprague-Dawley rats were raised in either an EC or an IC condition from 21 to 50 days of age, as has been described previously (Bowling et al., 1993). The EC rats were housed in groups of 8 in a large metal cage $(60 \times$ $120 \times 45 \mathrm{~cm}$ high), with pine chips on the floor and various objects made of metal or hard plastic. The objects consisted of various toys (e.g., rattles, buckets, blocks, trucks, ladders) purchased from a local store, as well as assorted objects such as discarded milk jugs, tubing, and old cage materials. The objects were rearranged daily, with novel objects being introduced each day. The IC rats were housed individually in a standard metal cage $(17 \times$ $24 \times 20 \mathrm{~cm}$ high). At 50 days of age, both EC and IC rats were anesthetized and implanted with a chronic indwelling catheter into the jugular vein. The rats were injected intravenously with $\left[{ }^{3} \mathrm{H}\right]-d l$-amphetamine $(1 \mathrm{mg} / \mathrm{kg}$, $10 \mu \mathrm{Ci} / 250 \mathrm{~g}$ body weight; specific activity, $32 \mathrm{Ci} / \mathrm{mmol}$; National Institute on Drug Abuse, Rockville, MD) and then killed by rapid decapitation at 1,10 , or $30 \mathrm{~min}$ after injection. The whole brains were weighed and solubilized in 5 volumes of TS- 2 tissue solubilizer (Research Products International, Mount Prospect, IL) at $36^{\circ} \mathrm{C}$ in a shaking incubator. Two volumes of $7 \%$ benzoperoxide/ toluene were then added to the mixture. Following neutralization with glacial acetic acid, $2 \mathrm{ml}$ of the mixture were added to $8 \mathrm{ml}$ Aquasol and the radioactivity was determined by liquid scintillation spectrometry.

The results indicated that brain radioactivity was highest $1 \mathrm{~min}$ after injection and declined approximately $50 \%$ by $30 \mathrm{~min}$ (Figure $1 \mathrm{~A}$ ). Brain radioactivity was significantly higher at 1 and $10 \mathrm{~min}$ after injection than at $30 \mathrm{~min}$ after injection $[F(2,54)=7.19, p<.01]$. There were no significant differences in radiolabel recovered from EC and $\mathrm{IC}$ rats at any interval after injection, suggesting that distribution of $\left[{ }^{3} \mathrm{H}\right]$-amphetamine to the brain during the first $30 \mathrm{~min}$ after injection is not altered by differential rearing.

In a parallel behavioral experiment, we prepared other groups of EC and IC rats with a jugular catheter and tested them for locomotor activity immediately following an acute intravenous injection of $1 \mathrm{mg} / \mathrm{kg} d$-amphetamine 


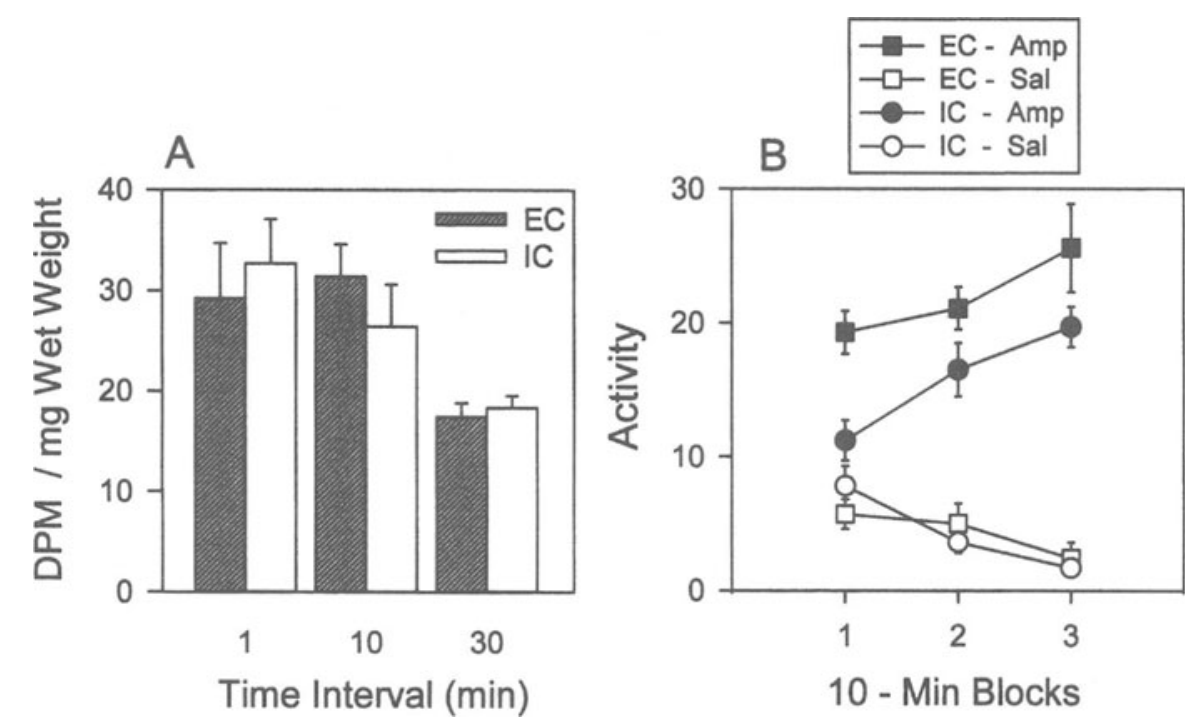

Figure 1. (A) Recovery of radioactivity in whole brain from EC and IC rats injected intravenously with $1 \mathrm{mg} / \mathrm{kg}\left[{ }^{3} \mathrm{H}\right]$-amphetamine and killed 1,10 , or 30 min after injection $(n=4-5$ per group at each time point). No significant differences between $\mathrm{EC}$ and $\mathrm{IC}$ rats were obtained. (B) Horizontal activity (number of line crosses) across 10-min blocks in EC and IC rats injected intravenously with $1 \mathrm{mg} / \mathrm{kg}$ amphetamine or saline $(n=6-9$ per group). Collapsed across all test blocks, EC rats given amphetamine were significantly more active than IC rats given amphetamine $(p<.05)$.

sulfate or saline. Locomotor activity was measured in a chamber $(24 \times 30 \times 45 \mathrm{~cm})$ with white wooden walls, wire mesh floor, and pine chip bedding beneath the floor. An observer recorded the number of times each rat crossed a line that bisected the chamber; activity was recorded for $30 \mathrm{~min}$ in 10-min blocks. Analysis of these data revealed a significant environmental condition $\times$ drug interaction $[F(1,29)=4.98, p<.05]$. $\mathrm{EC}$ and $\mathrm{IC}$ rats given saline did not differ significantly (Figure 1B). However, EC rats showed a significantly greater increase in amphetamine-induced activity than did IC rats.

Taken together, these experiments suggest that amphetamine-induced differences in locomotor activity between $\mathrm{EC}$ and IC rats following acute intravenous injection do not reflect an alteration in pharmacokinetics. This conclusion must be tempered somewhat because we did not determine how much recovered radioactivity represented $\left[{ }^{3} \mathrm{H}\right]$-amphetamine or $\left[{ }^{3} \mathrm{H}\right]$-metabolites. However, other work has shown that within the 30 -min interval examined, amphetamine accumulates rapidly in the brain following intravenous administration (Melega, Williams, Schmitz, DiStefano, \& Cho, 1995) and brain accumulation of the major metabolite $p$-hydroxyamphetamine is negligible (Kuhn, Schanberg, \& Breese, 1978). Moreover, the time-dependent decline in radiolabel observed in the present report parallels the first-order decay process that characterizes the loss of amphetamine from the brain for $60 \mathrm{~min}$ following intravenous administration in rats (Melega et al., 1995), suggesting that the radiolabel recovered from the brain in the present experiment represented primarily amphetamine. Thus, rather than reflecting a pharmacokinetic alteration, the difference between EC and IC rats in amphetamine-induced locomotor activity likely reflects an alteration intrinsic to the neural circuitry that mediates the behavioral response.

\section{Environment-Induced Changes in Nucleus Accumbens Function: In Vivo Study}

There is a wealth of evidence that environmental enrichment alters cortical neuroanatomy and higher level learning processes. More recent work has shown that environmental enrichment also affects subcortical structures, including the nucleus accumbens. Although accumbal dopamine receptor levels are unaltered (Bardo \& Hammer, 1991), environmental enrichment increases the overall functional activity of the nucleus accumbens assessed in glucose utilization studies (Gonzalez-Lima, Ferchmin, Eterovic, \& Gonzalez-Lima, 1994). This increase in metabolic activity is apparent even when EC rats are rested in a standard individual home cage following injection of $\left[{ }^{14} \mathrm{C}\right] 2$-deoxyglucose, indicating that basal neuronal activity is enhanced following a period of environmental enrichment. However, it is not known whether this increase in glucose utilization reflects a specific activation of mesoaccumbal dopamine neurons.

To examine the effect of differential rearing on amphetamine-stimulated release of dopamine in the nucleus accumbens, in vivo microdialysis in chloral hydrate anesthetized EC and IC rats was used. We utilized an anesthetized preparation, rather than an unanesthetized preparation, in order to avoid the possibility that amphetamineinduced differences in locomotor activity might be 


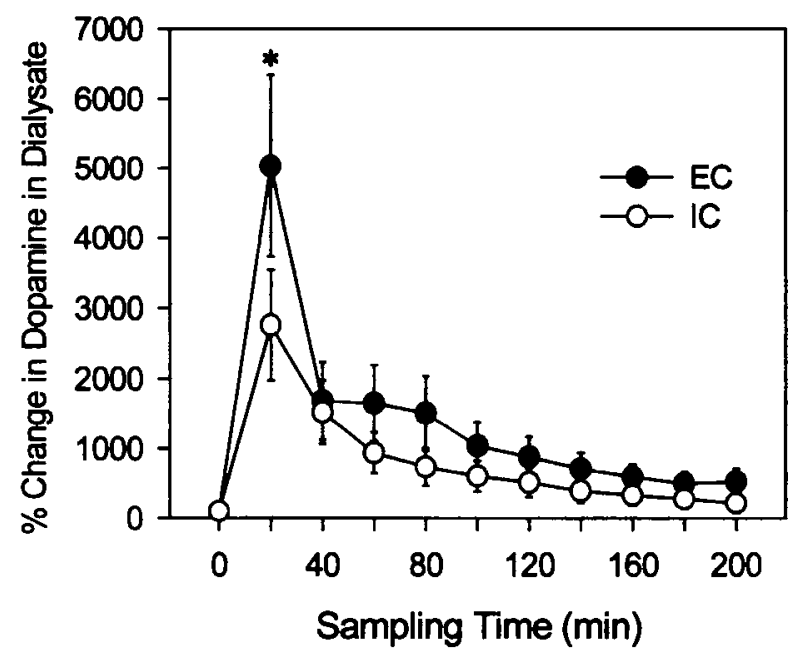

Figure 2. Dopamine levels in dialysate, expressed as a percent change from basal level, collected from the ventral striatum across 20-min samples in anesthetized EC and IC rats $(n=7-8$ per group) following intravenous amphetamine $(5 \mathrm{mg} / \mathrm{kg})$ at time 0 . Asterisk represents significant difference from IC rats at the first sampling interval following amphetamine $(p<.05)$.

responsible for any differences in dopamine release. Male Sprague-Dawley rats were reared from 21 to 55 days of age in EC or IC groups and were then prepared with a jugular catheter while under anesthesia $(100 \mathrm{mg} / \mathrm{kg}$ ketamine, $10 \mathrm{mg} / \mathrm{kg}$ diazepam). After 2 days of recovery, the animals were anesthetized again with chloral hydrate (initial dose of $400 \mathrm{mg} / \mathrm{kg}$, i.p., with supplemental doses as needed to maintain anesthesia) and a 2-mm microdialysis probe (CMA/12, Stockholm) was stereotaxically lowered into the ventral striatum, with the tip aimed at the nucleus accumbens (stereotaxic coordinates relative to bregma were $1.0 \mathrm{~mm}$ anterior, $2.0 \mathrm{~mm}$ lateral, $7 \mathrm{~mm}$ below dura; incisor bar $-3.3 \mathrm{~mm}$ ). The probe was perfused continually with artificial cerebrospinal fluid at a rate of $1 \mu \mathrm{l} / \mathrm{min}$ and sample collection ( $20 \mu \mathrm{l} / \mathrm{sample}$, $20 \mathrm{~min}$ ) began $2 \mathrm{~h}$ after probe insertion. Although the basal rates of dopamine release were not equilibrated completely within $2 \mathrm{~h}$, we began sampling at this interval in order to limit the overall duration of anesthetic treatment needed to complete the data collection. The first three samples were used to measure basal levels of dopamine in the dialysate determined by high-performance liquid chromatography with electrochemical detection (HPLC-EC); the detection limit of the system was typically 0.05 pmoles $/ 20 \mu \mathrm{l}$ dialysate. Following baseline sampling, $d$-amphetamine sulfate ( 1 or $5 \mathrm{mg} / \mathrm{kg}$, i.v.) was injected and 20-min sample collection continued for a minimum of $3 \mathrm{~h}$. Probe placements were subsequently verified by histological analysis. These analyses indicated that probe tips were located in either the accumbal core or the interface of the accumbal core/shell, the "shore." In all cases, the probe extended dorsally into the overlying ventral striatum.
Results from the in vivo microdialysis experiment revealed no significant environment-induced differences in extracellular dopamine levels in baseline dialysate samples. The basal levels of dopamine $(M \pm S E M)$ in the dialysate were $0.28 \pm 0.06 \mathrm{pmoles} / 20 \mu \mathrm{l}$ in the EC rats and $0.22 \pm 0.04 \mathrm{pmoles} / 20 \mu \mathrm{l}$ in the IC rats. As expected, amphetamine produced a dramatic rise in accumbal dopamine levels. There was no significant difference between the $\mathrm{EC}$ and IC rats following $1 \mathrm{mg} / \mathrm{kg}$ amphetamine (data not shown); however, the EC rats had a significantly greater rise in dopamine following $5 \mathrm{mg} / \mathrm{kg}$ amphetamine than did the IC rats (Figure 2). Analysis of the $5 \mathrm{mg} / \mathrm{kg}$ amphetamine data revealed a significant environmental condition $\times$ drug interaction $[F(10,150)=1.98, p<.05]$. Subsequent pairwise comparisons revealed that the difference between the EC and IC rats was significant during the first 20 -min sampling interval $(p<.05)$, but not at later sampling intervals.

Comparison of these microdialysis results with the locomotor results described previously suggests an apparent discrepancy in the effects of amphetamine across different doses. That is, in the locomotor experiment, an environment-induced difference in activity was found using $1 \mathrm{mg} / \mathrm{kg}$ amphetamine, whereas the microdialysis experiment showed no difference at this dose. Similarly, in a microdialysis study, Hall et al. (1998) found that accumbal dopamine release in differentially reared rats (group vs. individual home cages) was similar following low doses of amphetamine $(0.5-2 \mathrm{mg} / \mathrm{kg})$, even though these groups differed in locomotor response to amphetamine within this dose range (Ahmed, Stinus, Le Moal, \& Cador, 1995; Jones, Marsden, \& Robbins, 1990). However, Hall et al. did observe a difference between groupand individually housed rats in accumbal dopamine release following a high dose of amphetamine $(4 \mathrm{mg} / \mathrm{kg}$ ). On the basis of the discrepancy across amphetamine doses, it therefore appears that environment-induced changes in locomotor activity following amphetamine may not be related to changes in the dopamine-releasing effect of amphetamine. However, direct comparison between the results of the locomotor and microdialysis experiments is complicated, because in both the Hall et al. report and the present experiment, microdialysis was performed while the rats were under anesthesia. Anesthesia may influence both the level of dopamine in dialysate and the response to subsequent manipulations (Stahle, Collin, \& Ungerstedt, 1990). This could explain why a higher dose of amphetamine was required in order to observe an environment-induced difference in the microdialysis experiment as opposed to the locomotor experiment.

\section{Environment-Induced Changes in \\ Nucleus Accumbens Function: In Vitro Studies}

To identify the potential neuropharmacological mechanisms that may underlie the behavioral differences obtained in EC and IC rats, the functional activity of the dopaminergic system was examined using several in vitro 
Table 1

Stimulation-Evoked DOPAC Overflow from Striatal and Nucleus Accumbens Slices Obtained From EC and IC rats

\begin{tabular}{|c|c|c|c|c|c|}
\hline \multirow{3}{*}{$\begin{array}{c}\text { No. Pulses } \\
\text { Applied }\end{array}$} & \multirow{3}{*}{$\begin{array}{l}\text { Group } \\
(n=8) \\
\end{array}$} & \multicolumn{4}{|c|}{ DOPAC Overflow (pg/mg/min) } \\
\hline & & \multicolumn{2}{|c|}{ Striatum } & \multicolumn{2}{|c|}{ Nucleus Accumbens } \\
\hline & & $M$ & $S E M$ & $M$ & $S E M$ \\
\hline \multirow[t]{2}{*}{15} & EC & 60 & 8 & 64 & 11 \\
\hline & IC & 68 & 8 & 39 & 8 \\
\hline \multirow[t]{2}{*}{60} & $\mathrm{EC}$ & 281 & 39 & 181 & 35 \\
\hline & IC & 253 & 17 & 145 & 17 \\
\hline \multirow[t]{2}{*}{300} & EC & 398 & 75 & 242 & 26 \\
\hline & IC & 433 & 55 & 334 & 43 \\
\hline
\end{tabular}

Note-DOPAC, dihydroxyphenylacetic acid; EC, environmentally "enriched" condition; IC, environmentally "impoverished" condition.

techniques. In a previous report, no difference was observed between EC and IC rats in the effect of amphetamine on electrically evoked dopamine overflow in tissue slices from either the nucleus accumbens or the striatum (Bardo et al., 1995). However, since dopamine overflow in this previous report represented the net effect of both dopamine release and reuptake, it was not possible to determine whether environmental enrichment had a differential effect on either of these individual components that regulate extracellular dopamine levels. Furthermore, the dopamine transporter (DAT) has received attention as a target for psychostimulant drugs, because the mechanism of action of amphetamine is to reverse the transporter to evoke dopamine release from the presynaptic terminal (Liang \& Rutledge, 1982; Sulzer et al., 1995). Thus, subsequent experiments were conducted to determine whether there are environment-induced differences in (1) dopamine release assessed over a range of electrical stimulation currents; (2) functional activity of the dopamine autoreceptor that modulates release; and (3) functional activity of the DAT that transports dopamine into the nerve terminal from the extracellular space.

Using previously published methods (Gerhardt, Dwoskin, \& Zahniser, 1989), EC and IC rats were killed by rapid decapitation, and coronal slices $(0.5-\mathrm{mm}$ thickness) of the nucleus accumbens and striatum were incubated in Krebs' buffer for $60 \mathrm{~min}$ in a metabolic shaker at $34^{\circ} \mathrm{C}$ to allow for recovery of responsiveness and energy stores. The slices were transferred to a glass superfusion chamber containing two platinum electrodes and were superfused at a rate of $1 \mathrm{ml} / \mathrm{min}$ with aerated Krebs' buffer maintained at $34^{\circ} \mathrm{C}$ until the basal dopamine outflow sta- bilized. To assess stimulation-evoked dopamine release, slices were depolarized with 15,60 , or 300 unipolar pulses applied at $1 \mathrm{~Hz}(20 \mathrm{~mA}, 2-\mathrm{msec}$ duration). Fifteen consecutive samples $(1 \mathrm{ml})$ followed by 3 samples at $5-\mathrm{min}$ intervals were collected to determine electrical stimulationevoked overflow. To assess autoreceptor function, in other experiments, slices were superfused for $30 \mathrm{~min}$ prior to the electrical stimulation $(60$ pulses, $1 \mathrm{~Hz}$ ) with buffer containing the $\mathrm{D}_{2}$ dopamine agonist pergolide $(0.1-$ $100 \mathrm{nM}$ ). Following stimulation, 15 consecutive samples followed by 3 samples at 5 -min intervals were collected to determine the modulatory effect of pergolide on stimulation-evoked overflow from accumbal and striatal slices. The concentration of endogenous dopamine and DOPAC in superfusate and tissue slices was determined using HPLC-EC.

In these experiments, stimulation-evoked DOPAC overflow was measured, rather than dopamine overflow, because dopamine is not detectable in superfusate in response to electrical stimulation in the absence of an uptake inhibitor. In both the striatal and the nucleus accumbens slices, DOPAC overflow was not different between EC and IC groups (Table 1). However, an analysis of variance revealed significant main effects of electrical stimulation level $[F(2,42)=57.48, p<.0001]$ and brain region $[F(1,42)=18.96, p<.001]$, as well as a significant stimulation level $\times$ region interaction $[F(2,42)=3.52$, $p<.05]$. Pairwise comparisons, collapsed across environmental conditions, indicated that when 60 and 300 pulses were applied, DOPAC overflow was greater from the striatum than from the nucleus accumbens. The concentration of DOPAC remaining in the slice after stimulation was also greater in the striatum than in the nucleus accumbens $[F(1,53) p<.0001]$. No differences in tissue concentration of dopamine or DOPAC levels were evident between EC and IC rats (Table 2).

The presence of pergolide in the superfusion buffer did not alter basal DOPAC outflow from striatal or accumbal slices obtained from either EC or IC rats (data not shown). As expected, pergolide inhibited stimulation-evoked DOPAC overflow in a concentration-dependent manner in the striatal slices [for 0,1 , and $3 \mathrm{nM}, F(2,20) 3.87, p<$ .05 ; for 0,10 , and $100 \mathrm{nM}, F(2,28)=67.75, p<.0001]$ and in the nucleus accumbens slices [for $0,0.1,0.3$, and $1.0 \mathrm{nM}, F(3,63)=9.50, p<.0001$; for 0,10 , and $100 \mathrm{nM}$, $F(2,26)=43.01, p<.0001]$. However, the pergolideinduced inhibition of stimulation-evoked overflow was not

Table 2

Dopamine and DOPAC Concentration in Striatum and Nucleus Accumbens in EC and IC Rats

\begin{tabular}{|c|c|c|c|c|c|c|c|c|}
\hline \multirow{3}{*}{$\begin{array}{c}\text { Group } \\
(n=8)\end{array}$} & \multicolumn{4}{|c|}{ Dopamine ( $\mathrm{ng} / \mathrm{mg}$ wet weight) } & \multicolumn{4}{|c|}{ DOPAC (ng/mg wet weight) } \\
\hline & \multicolumn{2}{|c|}{ Striatum } & \multicolumn{2}{|c|}{ Nucleus Accumbens } & \multicolumn{2}{|c|}{ Striatum } & \multicolumn{2}{|c|}{ Nucleus Accumbens } \\
\hline & $M$ & $\overline{S E M}$ & $\bar{M}$ & $S E M$ & $\bar{M}$ & $S \overline{S E M}$ & $M$ & $S E M$ \\
\hline$\overline{\mathrm{EC}}$ & 8.8 & 0.9 & 3.0 & 0.3 & 0.63 & 0.05 & 0.46 & 0.05 \\
\hline IC & 8.7 & 0.8 & 3.1 & 0.3 & 0.64 & 0.05 & 0.50 & 0.03 \\
\hline
\end{tabular}

Note-DOPAC, dihydroxyphenylacetic acid; EC, environmentally "enriched" condition; IC, environmentally "impoverished" condition. 
Table 3

Pergolide-Induced Inhibition of Stimulation-Evoked

DOPAC Overflow From Striatal and Nucleus Accumbens Slices Obtained From EC and IC Rats

\begin{tabular}{|c|c|c|c|c|c|}
\hline \multirow{3}{*}{$\begin{array}{l}\text { Pergolide } \\
\text { Concentration } \\
\text { (nM) }\end{array}$} & \multirow{3}{*}{$\begin{array}{c}\text { Group } \\
(n=6-8)\end{array}$} & \multicolumn{4}{|c|}{ DOPAC Overflow (pg/mg/min) } \\
\hline & & \multicolumn{2}{|c|}{ Striatum } & \multicolumn{2}{|c|}{$\begin{array}{l}\text { Nucleus } \\
\text { Accumbens }\end{array}$} \\
\hline & & $M$ & SEM & $M$ & $S E M$ \\
\hline \multirow[t]{2}{*}{0} & $\mathrm{EC}$ & 259 & 25 & 144 & 18 \\
\hline & IC & 257 & 22 & 184 & 18 \\
\hline \multirow[t]{2}{*}{0.1} & EC & & & 108 & 14 \\
\hline & IC & & & 125 & 27 \\
\hline \multirow[t]{2}{*}{0.3} & EC & & & 116 & 17 \\
\hline & IC & & & 112 & 21 \\
\hline \multirow[t]{2}{*}{1} & EC & 159 & 15 & 79 & 10 \\
\hline & IC & 224 & 28 & 109 & 20 \\
\hline \multirow[t]{2}{*}{10} & $\mathrm{EC}$ & 102 & 23 & 24 & 9 \\
\hline & IC & 83 & 12 & 37 & 14 \\
\hline \multirow[t]{2}{*}{100} & EC & 41 & 6 & 23 & 8 \\
\hline & IC & 19 & 8 & 3 & 2 \\
\hline
\end{tabular}

Note-DOPAC, dihydroxyphenylacetic acid; EC, environmentally "enriched" condition; IC, environmentally "impoverished" condition.

different between EC and IC rats either in the striatum or the nucleus accumbens (Table 3 ).

To assess DAT function in the striatum, we determined the kinetic parameters $\left(\mathrm{K}_{\mathrm{m}}\right.$ and $\left.\mathrm{V}_{\max }\right)$, as well as the ability of cocaine, BTCP, DFP, and GBR 12935 to inhibit $\left[{ }^{3} \mathrm{H}\right]$-dopamine transport into the presynaptic nerve terminal, using a modification of a previously published method (Masserano, Venable, \& Wyatt, 1994). Striatum was used in these initial studies because of the high density of DAT protein in this brain region. Striatum was homogenized in $0.32 \mathrm{M}$ sucrose and $5 \mathrm{mM}$ sodium bicarbonate (pH 7.4) with a Teflon pestle and centrifuged at $2,000 \mathrm{~g}$ for $10 \mathrm{~min}$ at $4^{\circ} \mathrm{C}$. The supernatant was centrifuged at $20,000 \mathrm{~g}$ for $15 \mathrm{~min}$ at $4^{\circ} \mathrm{C}$, and the resulting pellet was resuspended in buffer containing (in $\mathrm{mM}$ ) $125 \mathrm{NaCl}, 5$ $\mathrm{KCl}, 1.5 \mathrm{MgSO}_{4}, 1.25 \mathrm{CaCl}_{2}, 1.5 \mathrm{KH}_{2} \mathrm{PO}_{4}, 10 d$-glucose, 25 HEPES, 0.1 EDTA, 0.1 pargyline, and 0.1 ascorbic

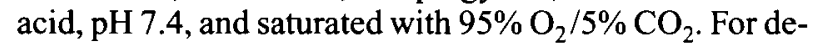
termining $\mathrm{K}_{\mathrm{m}}$ and $\mathrm{V}_{\max }$, aliquots of synaptosomes $(50 \mu \mathrm{l}$, containing $20 \mu \mathrm{g}$ of protein) were incubated in a metabolic shaker at $34^{\circ} \mathrm{C}$ for $10 \mathrm{~min}$ in the absence and presence of varying concentrations of $\left[{ }^{3} \mathrm{H}\right]$-dopamine $(0.01 \mathrm{nM}-$ $10 \mu \mathrm{M})$. For inhibition studies and the determination of $\mathrm{K}_{\mathrm{i}}$, the synaptosomes were preincubated with GBR 12935 $(10 \mathrm{nM}-0.1 \mathrm{mM})$ for $10 \mathrm{~min}$, followed by incubation with dopamine $\left(\left[{ }^{3} \mathrm{H}\right]\right.$-dopamine/unlabeled dopamine, final concentration $0.11 \mu \mathrm{M}$ ) for $10 \mathrm{~min}$ at $34^{\circ} \mathrm{C}$. In both kinetic and inhibition studies, the uptake reaction was terminated by the addition of $3 \mathrm{ml}$ of ice-cold buffer containing $1 \mathrm{mM}$ catechol and rapid filtration through a Whatman GF/B filter using a Brandell cell harvester. Radioactivity was determined by liquid scintillation spectrometry.

No differences were observed between EC and IC rats for either $K_{m}(0.88 \pm 0.09$ and $0.80 \pm 0.16 \mathrm{M}$, respectively) or $V_{\max }(67.9 \pm 2.24$ and $62.7 \pm 3.92 \mathrm{pmol} /$ $\min / \mathrm{mg}$, respectively), indicating that DAT functions similarly in differentially reared rats. Furthermore, there were no differences between EC and IC rats in the ability of cocaine, BTCP, or DFP to inhibit dopamine uptake (data not shown). Importantly, GBR 12935, a selective DAT inhibitor, was found to be significantly more potent in blocking dopamine uptake in EC rats than in IC rats (Figure 3). Since the other transport inhibitors did not result in a significant difference between EC and IC rats, GBR 12935 may interact with a different site on the DAT protein from that for the other inhibitors. Another difference between GBR 12935 and the other transport inhibitors tested is that GBR 12935 also inhibits dopamine transport into synaptic vesicles by interacting with the vesicular monoamine transporter (VMAT2; Reith, Coffey, $\mathrm{Xu}, \&$ Chen, 1994). The ability of GBR 12935 to alter dopamine storage may explain why this compound, but not the other DAT inhibitors, more potently inhibited dopamine uptake in EC rats than in IC rats. GBR 12935 and cocaine have also been reported to have different behavioral effects (Elmer et al., 1996), suggesting that VMAT2 may be an important cellular target for future investigation in EC and IC rats. This conclusion is supported by recent work showing that VMAT2 knockout mice have a diminished response to the rewarding effect of amphetamine, but not cocaine (Takahashi et al., 1997).

\section{Conclusions and Implications \\ for Future Research}

Evidence has accumulated to indicate that environmental enrichment may alter the functional activity of the mesoaccumbal circuitry, as well as the incentive behaviors associated with this circuitry. As has been described in the present brief review, evidence of environmentally induced alterations in accumbal function comes from studies in which researchers have examined the behavioral 


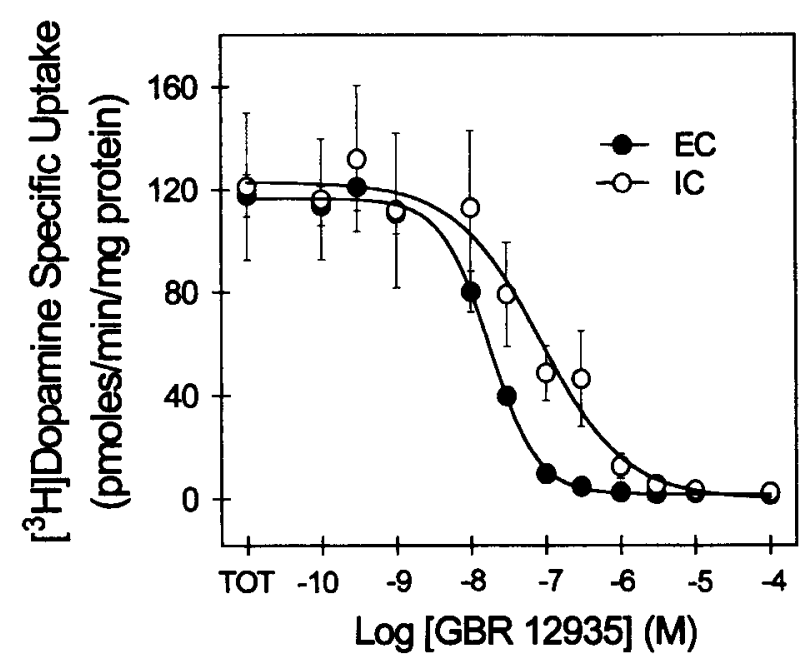

Figure 3. Inhibition of $\left[{ }^{3} \mathrm{H}\right]$-dopamine uptake by GBR 12935 in striatal synaptosomes prepared from EC and IC rats $(n=6-8$ per group). The potency of GBR 12935-induced inhibition of dopamine uptake was significantly greater in $E C$ rats $\left(K_{-}=8.48 \mathrm{nM}\right)$ than in $I C$ rats $\left(K_{\mathrm{i}}=36.6 \mathrm{nM}\right)(p<.05)$.

effects of psychostimulant drugs such as amphetamine. In general, EC rats are more sensitive than IC rats to the acute psychostimulant effects of amphetamine. This effect is not related to environmentally induced alterations in amphetamine pharmacokinetics, but appears to reflect some pharmacodynamic change in limbic function. One notable change is an enhanced amphetamine-induced release of dopamine in the nucleus accumbens of EC rats, measured by in vivo microdialysis. In contrast, amphetamineinduced release of accumbal dopamine measured in an in vitro slice preparation does not differ between EC and IC rats, suggesting that an intact accumbal circuitry may be necessary for one to observe environment-induced changes in accumbal function. Preliminary work using striatal synaptosomes indicates that environmental enrichment modifies the dopamine transporter, although further work is needed to determine whether a similar change occurs in the nucleus accumbens.

In the most detailed studies on cellular and anatomical changes induced by environmental enrichment, researchers have concentrated on cortical areas of the brain. This may have been prompted, at least in part, by an early seminal report claiming that the anatomical changes that occur in EC rats are most apparent in cortical areas (primarily the occipital cortex), whereas the rest of the brain tends to show little change in morphology (Bennett, Diamond, Krech, \& Rosenzweig, 1964). More recent work has shown that various cellular and anatomical changes also occur in subcortical structures, including the superior collicullus (Fuchs, Montemayer, \& Greenough, 1990), hippocampus (Olsson, Mohammed, Donaldson, Henriksson, \& Seckl, 1994), and striatum (Comery, Stamoudis, Irwin, \& Greenough, 1996). However, little is known presently about what precise cellular or anatom- ical changes, if any, occur in the nucleus accumbens following environmental enrichment. Given the present findings that environmental enrichment alters behavior, in vivo microdialysis, and DAT function, it seems that further cellular work examining VMAT2 function in the nucleus accumbens is needed. Such work would provide critical information about the mechanisms involved in environmental modulation of accumbal function.

\section{REFERENCES}

Ahmed, S. H., Stinus, L., Le Moal, M., \& Cador, M. (1995). Social deprivation enhances the vulnerability of male Wistar rats to stressorand amphetamine-induced behavioral sensitization. Psychopharmacology, 117, 116-124.

Bardo, M. T., Bowling, S. L., Rowlett, J. K., Manderscheid, P., BuxTon, S. T., \& Dwoskin, L. P. (1995). Environmental enrichment attenuates locomotor sensitization, but not in vitro dopamine release, induced by amphetamine. Pharmacology, Biochemistry \& Behavior, 51, 397-405.

BARDO, M. T., \& HAMMER, R. P. (1991). Autoradiographic localization of dopamine D1 and D2 receptors in rat nucleus accumbens: Resistance to differential rearing conditions. Neuroscience, 45, 281290.

Bennett, E. L., Diamond, M. C., Krech, D., \& Rosenzweig, M. R. (1964). Chemical and anatomical plasticity of brain. Science, 164, 610-619.

Bennett, E. L., Rosenzweig, M. R., \& Diamond, M. C. (1970). Time courses of effects of differential experience on brain measures and behavior of rats. In W. L. Byrne (Ed.), Molecular approaches to learning and memory (pp. 55-89). New York: Academic Press.

Black, J. E., Sirevaag, A. M., Wallace, C. S., Savin, M. H., \& GreeNOUGH, W. T. (1989). Effects of complex experience on somatic growth and organ development in rats. Developmental Psychobiology, 22, 727-752.

Bowling, S. L., \& BARDo, M. T. (1994). Locomotor and rewarding effects of amphetamine in enriched, social, and isolate reared rats. Pharmacology, Biochemistry \& Behavior, 48, 459-464.

Bowling, S. L., RowleTt, J. K., \& BARDO, M. T. (1993). The effect of environmental enrichment on amphetamine-stimulated locomotor activity, dopamine synthesis and dopamine release. Neuropharmacology, 32, 885-893.

Comery, T. A., Stamoudis, C. X., Irwin, S. A., \& Greenough, W. T. (1996). Increased density of multiple-head dendritic spines on medium-sized spiny neurons of the striatum in rats reared in a complex environment. Neurobiology of Learning \& Memory, 66, 93-96.

Crabre, J. C., Belknap, J. K., \& Buck, K. J. (1994, June). Genetic animal models of alcohol and drug abuse. Science, 264, 1715-1723.

Diamond, M. C., LaW, F., Rhodes, H., Linder, B., Rosenzweig, M. R., KRECH, D., \& BENNETT, E. L. (1966). Increases in cortical depth and glia numbers in rats subjected to enriched environments. Journal of Comparative Neurology, 128, 117-126.

Elmer, G. I., Brockington, A., Gorelick, D. A., Carrol, F. I., Rice, K. C., MatecKA, D., Goldberg, S. R., \& Rothman, R. B. (1996). Cocaine cross-sensitization to dopamine uptake inhibitors: Unique effects of GBR12909. Pharmacology, Biochemistry \& Behavior, 53, 911-918.

Fiala, B., SNOW, F. M., \& GReEnOugh, W. T. (1977). "Impoverished" rats weigh more than "enriched" rats because they eat more. Developmental Psychobiology, 10, 537-541.

Fowler, S. C., Johnson, J. S., Kallman, M. J., Liou, J. R., Wilson, M. C., \& HiKal, A. H. (1993). In a drug discrimination procedure isolation-reared rats generalized to lower doses of cocaine and amphetamine than rats reared in an enriched environment. Psychopharmacology, 110, 115-118.

Freeman, B. J., \& RaY, O. S. (1972). Strain, sex, and environmental effects on appetitively and aversively motivated learning tasks. Developmental Psychobiology, 5, 101-109. 
Fuchs, J. L., Montemayor, M., \& Greenough, W. T. (1990). Effect of environmental complexity on size of the superior colliculus. Behavioral \& Neural Biology, 54, 198-203.

Gerhardt, G. A., Dwoskin, L. P., \& Zahniser, N. R. (1989). Outflow and overflow of picogram level of endogenous dopamine and DOPAC from rat striatal slices: Improved methodology for studies of stimulus-evoked release and metabolism. Journal of Neuroscience Methods, 26, 217-227.

Gonzalez-Lima, F., Ferchmin, P. A., Eterovic, V. A., \& GonzalezLiMA, E. M. (1994). Metabolic activation of the brain of young rats after exposure to environmental complexity. Developmental Psy. chobiology, 27, 343-351.

Greenough, W. T., Madden, T. C., \& Fleischman, T. B. (1972). Effects of isolation, daily handling, and enriched rearing on maze learning. Psychonomic Science, 27, 279-280.

Hall, F. S., Wilkinson, L. S., Humby, T., Inglis, W., Kendall, D. A., MARSDEN, C. A., \& RobBins, T. W. (1998). Isolation rearing in rats: Pre- and postsynaptic changes in striatal dopaminergic systems. Pharmacology, Biochemistry \& Behavior, 59, 859-872.

Hill, S. Y., \& Powell, B. J. (1976). Cocaine and morphine selfadministration: Effects of differential rearing. Pharmacology, Biochemistry \& Behavior, 5, 701-704.

JoNES, G. H., MARSDEN, C. A., \& RoBbins, T. A. (1990). Increased sensitivity to amphetamine and reward-related stimuli following social isolation in rats: Possible disruption of dopamine-dependent mechanisms of the nucleus accumbens. Psychopharmacology, 102, 364 372

Kuhn, C. M., Schanberg, S. M., \& Breese, G. R. (1978). Metabolism of amphetamine by rat brain tissue. Biochemical Pharmacology, 27, 343-351.

Liang, N. Y., \& RutLeDge, C. O. (1982). Comparison of the release of $\left[{ }^{3} \mathrm{H}\right]$ dopamine from isolated corpus striatum by amphetamine, fenfluramine and unlabeled dopamine. Biochemical Pharmacology, 31, 983-992.

LORE, R. K., \& LEvowitz, A. (1966). Differential rearing and free versus forced exploration. Psychonomic Science, 5, 421-422.

Masserano, J. M., Venable, D., \& Wyatt, R. J. (1994). Effects of chronic cocaine administration on $\left[{ }^{3} \mathrm{H}\right]$ dopamine uptake in the nucleus accumbens, striatum and frontal cortex of rats. Journal of Pharmacology \& Experimental Therapeutics, 270, 133-141.

Melega, W. P., Williams, A. E., Schmitz, D. A., DiStefano, E. W., \& CHO, A. K. (1995). Pharmacokinetic and pharmacodynamic analysis of the actions of $d$-amphetamine and $d$-methamphetamine on the dopamine terminal. Journal of Pharmacology \& Experimental Therapeutics, 272, 90-96.

Olsson, T., Mohammed, A. H., Donaldson, L. F., Henriksson, B. G., \& SECKL, J. R. (1994). Glucorticoid receptor and NGFI-A gene expression are induced in the hippocampus after environmental enrichment in adult rats. Molecular Brain Research, 23, 349-353.

Rebec, G. V., Christensen, J. R. C., Guerra, C., \& Bardo, M. T. (1997). Regional and temporal differences in real-time dopamine efflux in the nucleus accumbens during free-choice novelty. Brain Research, 776, 61-67.

REIGE, W. H., \& MoRimoto, H. (1970). Effects of chronic stress and differential environments upon brain weights and biogenic amine levels in rats. Journal of Comparative \& Physiological Psychology, 71, 396-404.
Reith, M. E., Coffey, L. L., XU, C., \& Chen, N. H. (1994). GBR 12909 and 12935 block dopamine uptake into brain synaptic vesicles as well as nerve endings. European Journal of Pharmacology, 253, 175-178.

RENNER, M. J., \& RosenzWeig M. R. (1986). Object interactions in juvenile rats (Rattus norvegicus): Effects of different experiential histories. Journal of Comparative Psychology, 100, 229-236.

RENNER, M. J., \& RosenzweIG, M. R. (1987). Enriched and impoverished environments: Effects on brain and behavior. New York: Springer-Verlag.

RoSENZWEIG, M. R., \& BENNETT, E. L. (1972). Cerebral changes in rats exposed individually to an enriched environment. Journal of Comparative \& Physiological Psychology, 80, 304-313.

Rosenzweig, M. R., KRECH, D., BennetT, E. L., \& Diamond, M. C. (1962). Effects of environmental complexity and training on brain chemistry and anatomy: A replication and extension. Journal of Comparative \& Physiological Psychology, 55, 429-437.

SirevaAg, A. M., \& GreENOUGH, W. T. (1988). A multivariate statistical summary of synaptic plasticity measures in rats exposed to complex, social and individual environments. Brain Research, 441, 386392.

Smith, J. K., Neill, J. C., \& Costall, B. (1997). Post-weaning housing conditions influence the behavioral effects of cocaine and $d$ amphetamine. Psychopharmacology, 131, 23-33.

Stahle, L., Collin, A. K., \& Ungerstedt, U. (1990). Effects of halothane anesthesia on extracellular levels of dopamine, dihydroxyphenylacetic acid, homovanillic acid and 5-hydroxyindoleacetic acid in rat striatum: A microdialysis study. Naunyn-Schmiedeberg's Archives of Pharmacology, 342, 136-140.

Sulzer, D., Chen, T. K., LaU, Y. Y., Kristensen, H., Rayport, S., \& EwING, A. (1995). Amphetamine redistributes dopamine from synaptic vesicles to the cytosol and promotes reverse transport. Journal of Neuroscience, 15, 4102-4108.

Takahashi, N., Miner, L. L., Sora, I., Ujike, H., Revay, R. S., KosTIC, V., JACKSON-LEWTS, V., PRZEDBORSKI, S., \& UHL, G. R. (1997). VMAT2 knockout mice: Heterozygotes display reduced amphetamineconditioned reward, enhanced amphetamine locomotion, and enhanced MPTP toxicity. Proceedings of the National Academy of Sciences, 94, 9938-9943.

Wallace, C. S., Kilman, V. L., Withers, G. S., \& Greenough, W. T. (1992). Increases in dendritic length in occipital cortex after 4 days of differential housing in weanling rats. Behavioral \& Neural Biology, 58, 64-68.

Widman, D. R., \& Roselinin, R. A. (1990). Restricted daily exposure to environmental enrichment increases the diversity of exploration. Physiology \& Behavior, 47, 57-62.

Winterfeld, K. T., Teuchert-Noodt, G., \& Dawirs, R. R. (1998). Social environment alters both ontogeny of dopamine innervation of the medial prefrontal cortex and maturation of working memory in gerbils (Meriones unguiculatus). Journal of Neuroscience Research, 52, 201-209.

ZiMMERBERG, B., \& BRETT, M. B. (1992). Effects of early environmental experience on self-administration of amphetamine and barbital. Psychopharmacology, 106, 474-478.

(Manuscript received September 1, 1998; revision accepted for publication March 13, 1999.) 